Seminar Nasional Penelitian dan Pengabdian kepada Masyarakat Universitas Sang Bumi Ruwa Jurai Tahun 2020

\title{
PENDAMPINGAN PERSIAPAN AKREDITASI PENDIDIKAN ANAK USIA DINI DAN PENDIDIKAN NON FORMAL PADA TAMAN KANAK-KAKAK TUNAS CEDIKIA GEDONG TATAAN PESAWARAN LAMPUNG
}

\author{
M. Fikri Akbar ${ }^{1}$, Fery Hendi Jaya ${ }^{2}$, Rosmaria Duwikola ${ }^{3}$ \\ Universitas Sang Bumi Ruwa Jurai \\ Administrasi Negara, Fakultas Ilmu Sosial dan Ilmu Politik \\ 1fikri.m.akbar@gmail.com, ${ }^{2}$ feryhendi_jaya@yahoo.co.id, ${ }^{3}$ putrikola8@gmail.com
}

\begin{abstract}
Abstrak
Salah satu tugas pokok dan fungsi Badan Akreditasi Nasional Pendidikan Non Formal (BAN-PNF) adalah melaksanakan akreditasi terhadap Pendidikan Anak Usia Dini (PAUD). Akreditasi adalah kegiatan penilaian kelayakan satuan beserta program PNF berdasarkan atas kriteria yang telah ditetapkan. Untuk menilai kelayakan tersebut disusun instrumen akreditasi yang mengacu pada Standar Nasional Pendidikan (SNP) sebagaimana ditetapkan melalui Peraturan Pemerintah Republik Indonesia Nomor 32 Tahun 2013 tentang Perubahan Peraturan Pemerintah Republik Indonesia Nomor 19 Tahun 2005, yang mencakup 8 (delapan) standar, yaitu 1) Standar Kompetensi Lulusan, 2) Standar Isi, 3) Standar Proses, 4) Standar Pendidik dan Tenaga Kependidikan, 5) Standar Sarana dan Prasarana, 6) Standar Pengelolaan, 7) Standar Pembiayaan dan 8) Standar Penilaian Pendidikan. Khusus PAUD, Standar Kompetensi Lulusan menggunakan istilah Standar Tingkat Pencapaian Perkembangan (TPP). Instrumen akreditasi digunakan untuk memeroleh data berkaitan dengan 8 (delapan) SNP yang menggambarkan kondisi PAUD secara obyektif. Untuk itu, instrumen ini harus diisi oleh pengelola PAUD atau pihak yang bertanggung jawab atas penyelenggaraan PAUD. Jawaban terhadap pertanyaan/pernyataan harus sesuai dengan prosedur akreditasi PAUD yang telah ditetapkan oleh BAN-PNF.
\end{abstract}

Kata kunci: Akreditasi dan Pendidikan

\begin{abstract}
One of the main tasks and functions of the National Accreditation Board for Non-Formal Education (BAN-PNF) is to carry out accreditation for Early Childhood Education (PAUD). Accreditation is an activity to assess the feasibility of a unit and PNF program based on predetermined criteria. To assess the feasibility of an accreditation instrument that refers to the National Education Standards (SNP) as stipulated in the Republic of Indonesia Government Regulation Number 32 of 2013 concerning Amendments to the Government Regulation of the Republic of Indonesia Number 19 of 2005, which includes 8 (eight) standards, namely 1) Standard Competencies of Graduates, 2) Content Standards, 3) Process Standards, 4) Educators and Education Personnel Standards, 5) Facilities and Infrastructure Standards, 6) Management Standards, 7) Financing Standards and 8) Educational Assessment Standards. Especially for PAUD, the Competency Standards for Graduates use the term Development Achievement Level Standards (TPP). Accreditation instruments are used to obtain data relating to 8 (eight) SNPs that describe the condition of PAUD objectively. For this reason, this instrument must be filled in by the PAUD manager or the party responsible for implementing PAUD. Answers to questions / statements must be in accordance with the PAUD accreditation procedure established by BAN-PNF.
\end{abstract}

Keyword: Accreditation and Education

PENDAHULUAN 
Peningkatan kualitas Pendidikan Anak Usia Dini dan Pendidikan Non Formal (PAUD dan PNF) menjadi keharusan yang perlu dikelola secara manajerial agar tujuan dan sasaran kelembagaannya dapat tercapai menuju ke arah perubahan fokus sekolah yang berkualitas, perubahan dari kelayakan jangka pendek menuju ke arah perbaikan mutu jangka panjang, serta mengantisipasi dampak negatif terhadap perubahan nilai-nilai budaya pendidikan pada tingkat anak usia dini.

Secara konseptual PAUD dipahami sebagai segenap upaya pendidik (orang tua, guru, dan orang dewasa lainnya) dalam membimbing, mengajarkan, dan memfasilitasi perkembangan dan belajar anak sejak lahir sampai dengan usia enam tahun melalui penyediaaan berbagai pengalaman dan rangsangan yang bersifat mengembangkan, terpadu dan menyeluruh sehingga anak dapat bertumbuh kembang secara sehat dan optimal sesuai dengan nilai dan norma kehidupan yang dianut masyarakat.

Prinsip-prinsip pendidikan dan pembelajaran anak usia dini dapat terwujud pada lembaga-lembaga pendidikan semacam ini. Bahkan lebih jauh, lembaga-lembaga pendidikan ini dapat menjalin hubungan baik secara sinergis antara para guru dan pegawai administrasi dengan orang tua murid, sehingga tidak saja dapat membenahi program-program pendidikannya sendiri, melainkan juga turut membina dan meningkatkan kemampuan para orang tua dalam mendidik anak-anak mereka di rumah. Kondisi semacam itu tentunya terjadi secara interaktif dan diharapkan bersinergis, yang tentunya dapat menyampaikan nuansa-nuansa sosio-emosi, etika dan moral kepada perserta didik secara baik dan benar.

Pelaksanaan akreditasi PAUD dan PNF yang berkualitas sudah menjadi kebutuhan dan merupakan penentuan standar mutu dan penilaian suatu lembaga pendidikan yang ada di Indonesia mulai dari tingkat PAUD dan PNF sampai dengan tingkat Lembaga Pendidikan oleh pihak di luar lembaga yang independen. Akreditasi juga diartikan sebuah upaya pemerintah untuk menstandarisasi dan menjamin mutu peserta didik sehingga lebih mudah mengikuti pada tahap pendidikan selanjutnya.

Oleh karena itu, peningkatan mutu PAUD dan PNF memang mebutuhkan pelaksanaan akreditasi yang benar-benar objektif dan bernilai guna secara admistratif. Sebab akreditasi juga bisa memberikan manfaat pada semua pihak, baik itu pemerintah, calon peserta didik atau orang tua. Melalui akreditasi, pemerintah bisa lebih mudah menjamin mutu lembaga pendidkan yang lulus dari PAUD atau PNF yang sudah terakreditasi. Saat ini masih banyak Paud dan PNF yang belum terakreditasi salah satunya Taman Kanak-kanak Tunas Cedikia yang beradapa di Desa Kurungan Nyawa Kecamatan Gedong Tataan Kabupaten Pesawan.

\section{METODE PENELITIAN}

Metode pelaksanaan kegiatan ini adalah presentasi definisi, cara kerja, manfaat, dan cara penggunaan serta cara pengisian aplikasi Sispena 2.0 dalam proses Akreditasi Taman-kanak Tunas Cendikia Desa Kurungan Nyawa Kecamatan Gedong Tataan Kabupaten Pesawaran Provinsi Lampung yang dilakukan Bandan Akreditasi Nasional. 
Seminar Nasional Penelitian dan Pengabdian kepada Masyarakat Universitas Sang Bumi Ruwa Jurai Tahun 2020

\section{HASIL DAN PEMBAHASAN}

Sesuai Undang-undang No.20 Tahun 2003 tentang sistem pendidikan nasional yang salah satu pasalnya mengesahkan bahwa pendidikan adalah suatu upaya pembinaan yang ditujukan kepada anak sejak lahir sampai dengan usia enam tahun yang dilakukan melalui pemberian rangsangan pendidikan untuk membantu pertumbuhan dan perkembangan jasmani dan rohani, agar anak memiliki kesiapan dalam memasuki pendidikan lebih lanjut.

Pendapat para ahli bahwa anak usia 0 sampai dengan 6 tahun merupakan masa keemasan, yang akan menentukan perkembangan anak selanjutnya. Untuk itu dalam mempersiapkan generasi mendatang maka sangat perlu pembinaan dan pelayanan bagi anak usia dini secara optimal dan merata di seluruh wilayah Indonesia. Pemerintah telah berupaya secara maksimal dalam memberikan pembinaan dan pelayanan kepada anak usia dini.

Pendidikan anak usia dini pada kenyataannya saat ini belum optimal dan belum menjangkau ke seluruh lapisan masyarakat. Kondisi tersebut belum sesuai dengan amanat GBHN Tahun 1999 yang menyatakan bahwa pemerintah perlu mempersiapkan sumber daya manusia sejak dini. Guna mengatasi permasalahan tersebut dengan cepat, maka Pemerintah melalui Departemen pendidikan Nasional membentuk institusi baru yang akan membina dan mengembangkan potensi anak usia dini yaitu Direktorat Pendidikan Anak Usia Dini yang bernaung dibawah Direktorat Jendral Pendidikan Non-Formal dan In-Formal. Dalam melaksanakan tugas dan fungsi Direktorat PAUD akan mengembangkan program-program pendidikan prasekolah melalui penitipan anak (PA). Kelompok bermain (KB) dan satuan PAUD sejenis (SPS). Hal ini sesuai dengan Undang-undang No. 20 Tahun 2003 dalam pasal 28 ayat 4 yang menegaskan bahwa pendidikan non formal berbentuk kelompok bermain (KB). Taman Penitipan Anak (TPA) dan bentuk lain yang sejenis.

Mengingat masih banyaj keluarga prasejahtera dan sejahtera I atas ekonomi sehingga banyak juga anak-anak usia dini yang kurang beruntung sehingga mereka tidak dapat kesempatan mengenyam pendidikan. Dalam rangka menindak lanjuti program pemerintah tersebut dan sebagai perpanjangan tangan pemerintah maka Taman Kanak-kanak (TK) dan Pendidikan Anak Usia Dini (PAUD) Tunas Cendikia memberikan kesempatan bagi anak-anak yang kurang beruntung tersebut untuk ikut bergabung dalam kelompok bermain yang memenuhi unsur-unsur pendidikan bagi anak-anak usia dini agar tumbuh secara optimal dan mempunyai kesiapan dalam memasuki pendidikan selanjutnya. 


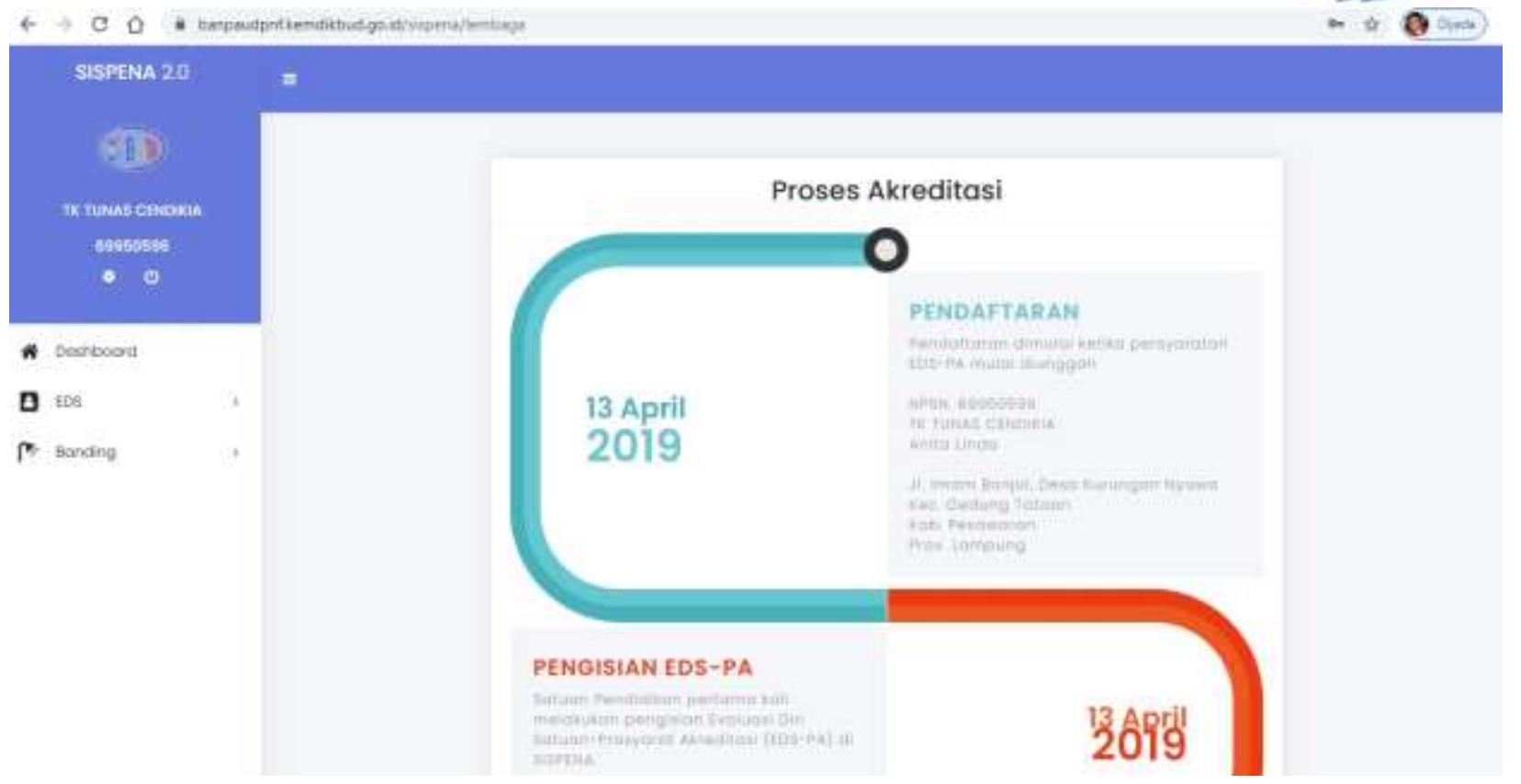

Penjelasan:

1. Pendidikan Non Formal adalah jalur pendidikan di luar pendidikan formal yang dapat dilaksanakan secara terstruktur dan berjenjang.

2. Pendidikan Non Formal meliputi pendidikan kecakapan hidup, pendidikan anak usia dini, pendidikan kepemudaan, pendidikan pemberdayaan perempuan, pendidikan keaksaraan, pendidikan keterampilan dan pelatihan kerja, pendidikan kesetaraan, serta pendidikan lain yang ditujukan untuk mengembangkan kemampuan peserta didik.

3. Satuan Pendidikan Non Formal adalah kelompok layanan pendidikan yang menyelenggarakan pendidikan pada jalur non formal pada setiap jenjang dan jenis pendidikan.

4. Satuan Pendidikan Non Formal terdiri dari atas lembaga kursus, lembaga pelatihan, kelompok belajar, pusat kegiatan belajar masyarakat, dan majelis taklim, serta satuan pendidikan yang sejenis.

5. Jenjang Pendidikan adalah tahapan pendidikan yang ditetapkan berdasarkan tingkat perkembangan peserta didik, tujuan yang akan dicapai, dan kemampuan yang dikembangkan.

6. Jenis Pendidikan adalah kelompok yang didasarkan pada kekhususan tujuan pendidikan suatu satuan pendidikan.

7. Pendidikan Anak Usia Dini (PAUD) adalah suatu upaya pembinaan yang ditujukan kepada anak sejak lahir sampai dengan usia enam tahun yang dilakukan melalui pemberian rangsangan pendidikan untuk membantu pertumbuhan dan perkembangan jasmani serta rohani agar anak memiliki kesiapan dalam memasuki pendidikan lebih lanjut.

8. Kurikulum adalah seperangkat rencana dan pengaturan mengenai tujuan, isi, dan bahan pelajaran serta cara yang digunakan sebagai pedoman penyelenggaraan kegiatan pembelajaran untuk mencapai tujuan pendidikan tertentu.

9. Struktur Kurikulum merupakan pengorganisasian Kompetensi Inti, Kompetensi Dasar, 
muatan Pembelajaran, mata pelajaran, dan beban belajar pada setiap satuan pendidikan dan program pendidikan.

10. Peserta Didik adalah anggota masyarakat yang berusaha mengembangkan potensi diri melalui proses pembelajaran yang tersedia pada setiap jalur, jenjang dan jenis Program Kursus dan Pelatihan.

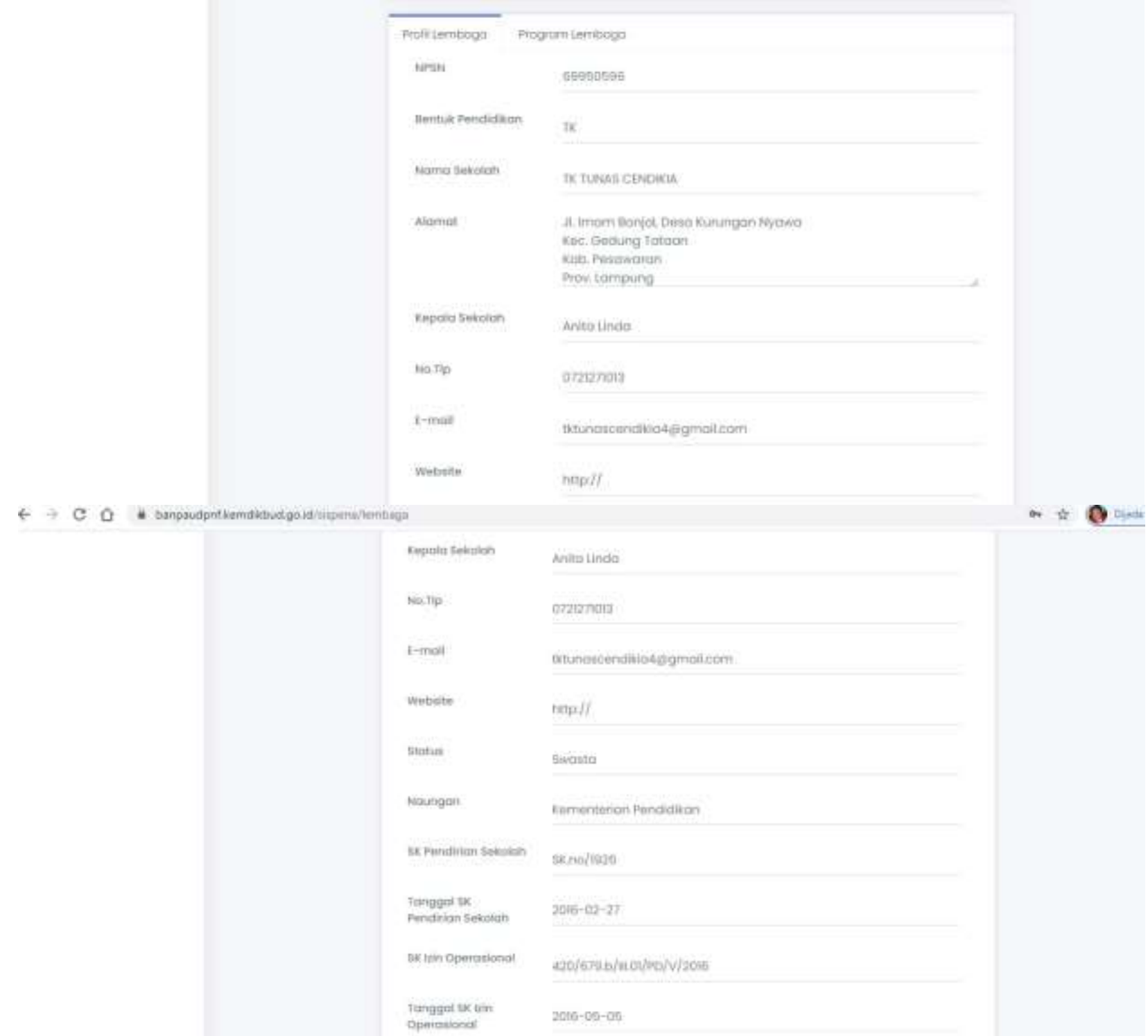

11. Tenaga Kependidikan adalah anggota masyarakat yang mengabdikan diri dan diangkat untuk menunjang penyelenggaraan pendidikan.Tenaga kependidikan meliputi pengelola satuan pendidikan, penilik, pamong belajar, pengawas, peneliti, pengembang, pustakawan, laboran, dan teknisi sumber belajar.

12. Pendidik adalah anggota masyarakat yang berkualifikasi sebagai guru, dosen, konselor, pamong belajar, widyaiswara, tutor, instruktur, fasilitator, dan sebutan lain yang sesuai dengan kekhususannya, serta berpartisipasi dalam menyelenggarakan pendidikan.

13. Penilaian pembelajaran adalah proses pengumpulan dan pengelolaan informasi untuk mengukur pencapaian hasil belajar peserta didik. 
14. Evaluasi Pendidikan adalah kegiatan pengendalian, penjaminan, dan penetapan mutu pendidikan terhadap berbagai komponen pendidikan pada setiap jalur, jenjang, dan jenis pendidikan sebagai bentuk pertanggungjawaban penyelenggaraan pendidikan.

15. Akreditasi adalah kegiatan penilaian kelayakan suatu program dalam satuan pendidikan berdasarkan kriteria yang telah ditetapkan. Akreditasi dilakukan atas dasar kriteria yang bersifat terbuka.

16. Badan Akreditasi Nasional Pendidikan Nonformal yang selanjutnya disebut BAN-PNF adalah badan evaluasi mandiri yang menetapkan kelayakan program dan/atau satuan pendidikan jalur Pendidikan Nonformal dengan mengacu pada Standar Nasional Pendidikan.

17. Sertifikat Akreditasi adalah dokumen formal atau satu set dokumen yang secara legal dapat dipertanggungjawabkan yang menyatakan pemberian akreditasi kepada satuan PNF untuk suatu Program PNF.

18. Simbol Akreditasi adalah simbol/logo akreditasi yang diterbitkan oleh BAN-PNF untuk digunakan oleh satuan PNF yang terakreditasi, yang menunjukkan status akreditasi mereka sekaligus mengindikasikan langsung kelayakan Lembaga Kursus dan Pelatihan.

19. Banding adalah permintaan dari lembaga penyelenggara PNF untuk mempertimbangkan kembali keputusan yang dirasakan merugikan yang dibuat BAN-PNF terkait dengan hasil penilaian status akreditasi PNF.

20. Asesor Akreditasi adalah seseorang yang mempunyai kualifikasi dan kompetensi yang relevan dengan tugas untuk melaksanakan akreditasi terhadap kelayakan program dalam satuan PNF, baik secara perorangan maupun sebagai bagian dari tim akreditasi sesuai dengan persyaratan dan tugas yang ditetapkan oleh BAN-PNF.

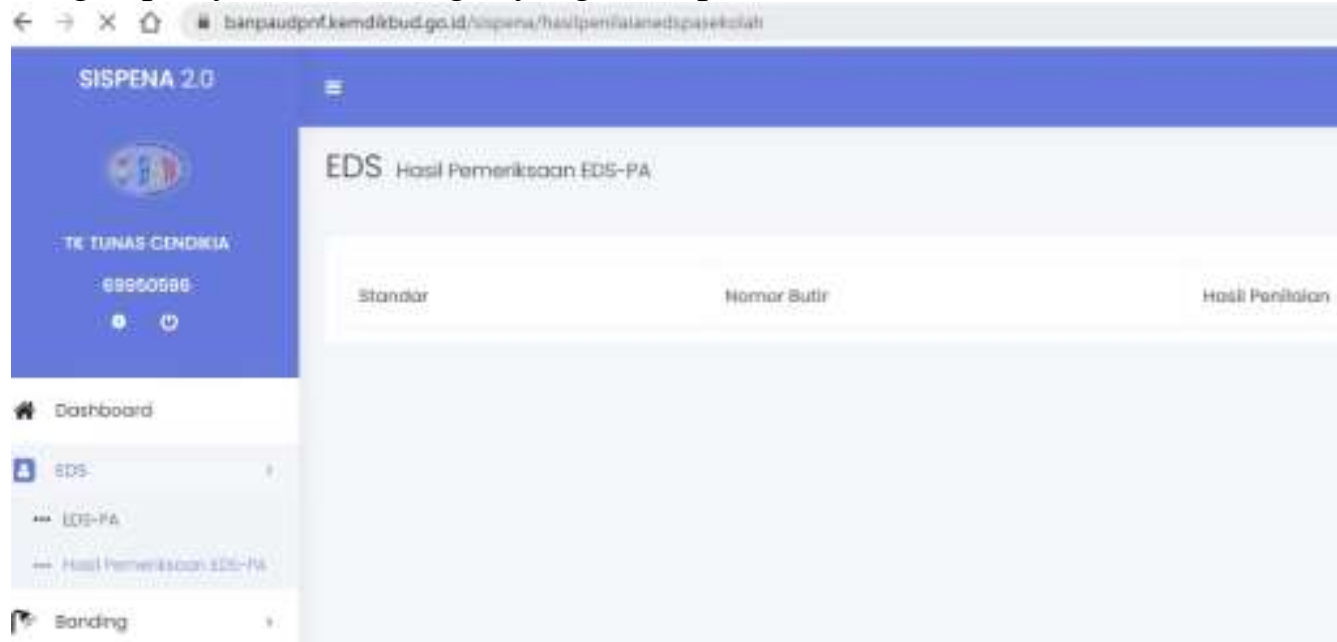

21. Sistem Penjaminan Mutu adalah dokumen dan rekaman kegiatan-kegiatan yang bertujuan untuk memenuhi atau melampaui standar nasional pendidikan yang mencakupi struktur organisasi, tanggung jawab, prosedur, proses dan sumber untuk menerapkan manajemen dan pengelolaan mutu, serta dilakukan secara bertahap, sistematis, dan terencana dalam suatu program penjaminan mutu yang memiliki target dan kerangka waktu yang jelas.

22. Panduan Mutu adalah suatu dokumen yang berisi kebijakan mutu, sistem mutu, dan 
pelaksanaan mutu dalam suatu organisasi. Panduan mutu dapat juga dibuat dalam bentuk dokumen lain yang berhubungan dengan pengaturan mutu PNF.

23. Surveilen adalah kegiatan penilaian ulang kelayakan program dalam satuan PNF yang dilakukan oleh BAN-PNF sehubungan dengan aspek dan lingkup akreditasi setelah dilakukan akreditasi.

24. Standar Nasional Pendidikan adalah kriteria minimal tentang sistem pendidikan di seluruh wilayah hukum Negara Kesatuan Republik Indonesia.

25. Kompetensi adalah seperangkat sikap, pengetahuan, dan keterampilan yang harus dimiliki, dihayati, dan dikuasai oleh Peserta Didik setelah mempelajari suatu muatan pembelajaran, menamatkan suatu program, atau menyelesaikan satuan pendidikan tertentu.

26. Peserta Didik PAUD adalah anak usia 0-6 tahun yang berusaha mengembangkan potensi diri melalui proses pembelajaran yang tersedia pada satuan PAUD.

27. Standar Tingkat Pencapaian Perkembangan adalah tingkat pencapaian perkembangan sebagai aktualisasi potensi aspek perkembangan anak sesuai dengan tahap perkembangannya masing-masing.

28. Standar Isi adalah kriteria mengenai ruang lingkup materi dan tingkat Kompetensi untuk mencapai Kompetensi lulusan pada jenjang dan jenis pendidikan tertentu.

29. Standar Proses adalah kriteria mengenai pelaksanaan pembelajaran pada satu satuan pendidikan untuk mencapai Standar Kompetensi Lulusan.

30. Standar Pendidik dan Tenaga Kependidikan adalah kriteria mengenai kelayakan kualifikasi dan kompetensi yang relevan dari pendidik/instruktur dan tenaga kependidikan/pengelola pada Satuan Kursus dan Pelatihan.

31. Standar Sarana dan Prasarana adalah kriteria mengenai ruang belajar, tempat beribadah, perpustakaan, laboratorium, bengkel kerja, tempat berkreasi, media pembelajaran, alat dan bahan ajar, serta sumber belajar lain, yang diperlukan untuk menunjang proses pembelajaran, termasuk penggunaan teknologi informasi dan komunikasi.

32. Standar Pengelolaan adalah kriteria mengenai perencanaan, pelaksanaan, dan pengawasan kegiatan pendidikan pada tingkat satuan pendidikan, agar tercapai efisiensi dan efektivitas penyelenggaraan pendidikan.

33. Standar Penilaian Pendidikan adalah kriteria mengenai mekanisme, prosedur, dan instrumen penilaian hasil belajar Peserta Didik.

34. Standar Pembiayaan adalah kriteria mengenai komponen dan besarnya biaya operasi satuan pendidikan yang berlaku selama satu tahun.

35. Dokumen adalah format yang menjadi perencanaan untuk dilaksanakan (sebelum diisi data), seperti formulir, panduan mutu, prosedur, instruksi kerja dan fotokopi.

36. Rekaman adalah catatan hasil pelaksanaan dan pengisian dari dokumen, seperti hasil formulir yang telah diisi, instruksi kerja dengan fotokopi yang telah diisi.

Salah satu tugas pokok dan fungsi Badan Akreditasi Nasional Pendidikan Non Formal (BAN-PNF) adalah melaksanakan akreditasi terhadap Pendidikan Anak Usia Dini (PAUD). Akreditasi adalah kegiatan penilaian kelayakan satuan beserta program PNF berdasarkan atas kriteria yang telah ditetapkan. Untuk menilai kelayakan tersebut disusun instrumen akreditasi yang mengacu pada Standar Nasional Pendidikan (SNP) sebagaimana ditetapkan melalui Peraturan Pemerintah Republik Indonesia Nomor 32 Tahun 2013 tentang Perubahan Peraturan Pemerintah Republik Indonesia Nomor 19 Tahun 2005, yang mencakup 8 (delapan) standar, 
Seminar Nasional Penelitian dan Pengabdian kepada Masyarakat Universitas Sang Bumi Ruwa Jurai Tahun 2020

yaitu 1) Standar Kompetensi Lulusan, 2) Standar Isi, 3) Standar Proses, 4) Standar Pendidik dan Tenaga Kependidikan, 5) Standar Sarana dan Prasarana, 6) Standar Pengelolaan, 7) Standar Pembiayaan dan 8) Standar Penilaian Pendidikan. Khusus PAUD, Standar Kompetensi Lulusan menggunakan istilah Standar Tingkat Pencapaian Perkembangan (TPP).

Instrumen akreditasi digunakan untuk memeroleh data berkaitan dengan 8 (delapan) SNP yang menggambarkan kondisi PAUD secara obyektif. Untuk itu Taman Kanak-kanak Tunas Cendikia harus memenuhi standar tersebut, instrumen ini harus diisi oleh pengelola Taman Kanak-kanak Tunas Cendikia atau pihak yang bertanggung jawab atas penyelenggaraan PAUD. Jawaban terhadap pertanyaan/pernyataan yang diberikan Taman Kanak-kanak Tunas Cendikia harus sesuai dengan prosedur akreditasi PAUD yang telah ditetapkan oleh BAN-PNF.

\section{KESIMPULAN}

Akreditasi merupakan proses evaluasi dan penilaian secara komprehensif atas komitmen lembaga pendidikan Taman kanak-kanak Tunas Cendikia terhadap kualitas dan kapasitas pendidikan, untuk menentukan kelayakan program dan satuan pendidikan. Sejak perencanaan sampai evaluasi dan penilaian harus dilakukan dengan standar yang sama agar penilaian memiliki standar yang sama. Akreditasi juga menjadi sebuah kegiatan penting untuk menetapkan posisi PAUD dan PNF sebagai lembaga pendidikan yang memiliki standar.

\section{UCAPAN TERIMAKASIH}

Puji dan syukur penulis panjatkan kepada Tuhan Yang Maha Esa atas segala rahmat dan kasih karunia-Nya yang memberikan kesehatan dan kesempatan pada penulis sehingga laporan Pengabdian Kepada Masyarakat ini dapat diselesaikan dengan baik.

\section{DAFTAR PUSTAKA}

Saripudin, A. (2019). Kompetensi Guru Pendamping Paud Dalam Memenuhi Standar Layanan Paud Non Formal Di Kabupaten Tasikmalaya. Awlady: Jurnal Pendidikan Anak, 5(2), 63-77.

Tirtayani, L. A. (2018). Upaya Pendampingan Anak Berkebutuhan Khusus Pada LembagaLembaga Paud Di Singaraja, Bali. Proyeksi: Jurnal Psikologi, 12(2), 21-34.

Effawati, D. (2020). Peran Guru Pendamping Dalam Membantu Pembelajaran Paud Di Gugus Mawar Kec. Sukaraja Kab. Seluma. Genta Mulia: Jurnal Ilmiah Pendidikan, 11(2).

Khasanah, U., Badriyah, B., Rahardjo, S., Nurlaili, A., \& Hendriyani, F. (2019). Pendampingan Deteksi Dini Tumbuh Kembang Anak Dengan Menggunakan Sdidtk Pada Guru Paud Dan Tk Di Kecamatan Socah Kabupaten Bangkalan. Community Development Journal, 3(1), 27-32.

Tedjawati, J. M. (2011). Peran Himpaudi Dalam Pengembangan Paud. Jurnal Pendidikan Dan Kebudayaan, 17(1), 123-133.

Asmah, A., \& Wijayanti, R. (2018). Pendampingan Penerapan Model Pembelajaran Sentra Di Gugus Paud Iii Kecamatan Pakisaji Kabupaten Malang. Japi (Jurnal Akses Pengabdian Indonesia), 3(1), 42-47. 